\title{
Performance of CT in the Preoperative Diagnosis of Cervical Lymph Node Metastasis in Patients with Papillary Thyroid Cancer: A Systematic Review and Meta-Analysis
}

\author{
(D)C.H. Suh, (D).H. Baek, (D).J. Choi, and (D).H. Lee
}

\begin{abstract}
BACKGROUND AND PURPOSE: Ultrasound has become widely accepted as the first imaging technique used for the assessment of cervical lymph node metastasis in patients with papillary thyroid cancer. In this systematic review and meta-analysis, we evaluate the performance of CT for the preoperative diagnosis of cervical lymph node metastasis in patients with papillary thyroid cancer compared with ultrasound.
\end{abstract}

MATERIALS AND METHODS: Ovid-MEDLINE and EMBASE data bases were searched for studies regarding the use of CT to diagnose cervical lymph node metastasis. The diagnostic performance of CT, ultrasound, and combined CT/ultrasound was assessed by using level-by-level and patient-based analyses. We also performed meta-analyses on the basis of the central and lateral neck levels.

RESULTS: Nine eligible studies, including a total sample size of 1691 patients, were included. CT showed a summary sensitivity of $62 \%$ (95\% $\mathrm{Cl}, 52 \%-70 \%)$ and specificity of $87 \%(95 \% \mathrm{Cl}, 80 \%-92 \%)$ for diagnosing cervical lymph node metastasis when using level-by-level analysis. There was a positive correlation between the sensitivity and the false-positive rate (correlation coefficient, 0.807) because of the threshold effect. The summary sensitivity of combined CT/ultrasound (69\%; $95 \% \mathrm{Cl}, 61 \%-77 \%)$ was significantly higher than ultrasound (51\%; $95 \% \mathrm{Cl}, 42 \%-60 \%$ ), though the summary specificity did not differ.

CONCLUSIONS: The diagnostic performances of CT and ultrasound are similar, though CT and ultrasound combined are superior to ultrasound only. CT may be used as a complementary diagnostic method in addition to ultrasound for diagnosing cervical lymph node metastasis in patients with papillary thyroid cancer.

ABBREVIATIONS: HSROC = hierarchic summary receiver operating characteristic; QUADAS-2 = Quality Assessment of Diagnostic Accuracy Studies-2; US = ultrasound

$\mathbf{P}$ apillary thyroid cancer involves metastasis to cervical lymph nodes in up to $60 \%-70 \%$ of patients. ${ }^{1,2}$ The presence of cervical lymph node metastasis is also highly associated with local recurrence and cancer-specific mortality. ${ }^{3,4}$ Several studies have demonstrated that cervical lymph node metastasis had an unfavorable prognostic effect on survival in patients 45 years of age and older. ${ }^{5,6}$ According to the new American Thyroid Association guidelines, ${ }^{7}$ ultrasound (US) has become widely accepted as the first imaging technique used for the assessment of cervical lymph

Received April 1, 2016; accepted after revision August 22

From the Department of Radiology and Research Institute of Radiology (C.H.S., J.H.B., Y.J.C., J.H.L.), University of Ulsan College of Medicine, Asan Medical Center, Seoul, Republic of Korea; and Department of Radiology (C.H.S.), Namwon Medical Center, Namwon-Si, Republic of Korea.

Please address correspondence to Jung Hwan Baek, MD, PhD, Department of Radiology and Research Institute of Radiology, University of Ulsan College of Medicine, Asan Medical Center, 86 Asanbyeongwon-Gil, Songpa-Gu, Seoul 138-736, Republic of Korea; e-mail: radbaek@naver.com

三 Indicates article with supplemental on-line table.

http://dx.doi.org/10.3174/ajnr.A4967 node metastasis in patients with papillary thyroid cancer. A recent meta-analysis demonstrated that the sensitivity of US was $63 \%$ (95\% CI, 47\%-76\%), the specificity was $93 \%$ (95\% CI, 73\%$99 \%$ ), and the area under the curve was 0.81 (95\% CI, 0.77-0.84) by level-by-level analysis. ${ }^{8}$

However, because US is an operator-dependent technique, it is often difficult to evaluate the entire neck. Several US studies have reported variable and relatively low sensitivity for the assessment of central cervical lymph node metastasis. ${ }^{9-11}$ Normal anatomic structures, including the larynx, trachea, and areas deep in the clavicles, jaw, and sternum, cause significant acoustic shadowing. ${ }^{12}$ This results in limited US evaluation of the mediastinum and retropharyngeal area, regardless of clinical experience of the operator.

Contrast-enhanced CT is a standard imaging technique used for the assessment of cervical lymph node metastasis in head and neck cancer; however, CT was not recommended as a routine imaging technique for patients with papillary thyroid cancer. ${ }^{13}$ Nevertheless, several recent studies have reported the possibility 
of the complementary role of CT for the preoperative evaluation of cervical lymph node metastasis. ${ }^{14-22}$ According to the new American Thyroid Association guidelines, ${ }^{7}$ CT is currently recommended as an adjunct to US for patients with clinical suspicion of advanced disease, such as invasive primary tumor or clinically apparent, multiple, or bulky lymph node metastasis. Because the US examination is operator-dependent and it is difficult to evaluate deep anatomic structures, CT with contrast enhancement may be useful in delineating the extent of tumor involvement in the airway or esophagus as well as delineating extranodal tumor extension. Preoperative knowledge of these features of the primary tumor or metastases could significantly influence the surgical plan. ${ }^{7,23}$ Therefore, it is timely and necessary to collect currently available data regarding the diagnostic performance of CT in the preoperative diagnosis of cervical lymph node metastasis.

A meta-analysis is part of the systematic review and uses statistical methods to integrate the results of multiple original studies. ${ }^{24}$ Recently, the use of systematic review with meta-analyses is increasing in the field of radiology academic research (ie, diagnostic test accuracy). The main objectives of systematic review with meta-analyses are to obtain more valid, generalizable summary estimates and to identify and provide information on covariates that affect diagnostic accuracy tests. ${ }^{25-27}$ To the best of our knowledge, no systematic review with meta-analyses has assessed the role of using CT to diagnose cervical lymph node metastasis in patients with papillary thyroid cancer. Therefore, this systematic review with a meta-analysis evaluates the diagnostic performance of CT in the preoperative diagnosis of cervical lymph node metastasis in patients with papillary thyroid cancer compared with US.

\section{MATERIALS AND METHODS \\ Literature Search Strategy}

A computerized search of the MEDLINE and EMBASE data bases was performed to find relevant, original literature reports on the use of CT to diagnose cervical lymph node metastasis in patients with papillary thyroid cancer. We used the following search terms: ("thyroid cancer" OR "thyroid cancers" OR "thyroid carcinoma" OR "thyroid carcinomas”) AND (cervical lymph node metastasis OR cervical metastatic lymph node OR cervical metastatic lymphadenopathy) AND (ultrasonography OR sonography OR US OR "CT" OR CT). The beginning search date was not limited. Our search was limited to human patients and English language studies. We continued updating the literature search until November 29,2015 . To expand the search, we perused the bibliographies of the articles to identify other appropriate articles.

\section{Inclusion Criteria}

Studies that investigated the performance of CT in the preoperative diagnosis of cervical lymph node metastasis in patients with papillary thyroid cancer were eligible for inclusion. We included studies that satisfied all of the following criteria:

Population. Studies included $>10$ patients who underwent CT for papillary thyroid cancer before surgery. None of these patients had undergone previous operations of the head and neck.
Reference Standard. The level of cervical lymph nodes was determined according to the American Joint Committee on Cancer Cancer Staging Manual. ${ }^{28}$ Assignment of cervical lymph nodes was based on compartments, including the lateral compartment (levels I-V) and the central compartment (level VI). The CT criteria for cervical lymph node metastasis were as follows: strong enhancement without hilar vessel enhancement, heterogeneous enhancement, calcification, and cystic or necrotic change. ${ }^{29}$ The US criteria for cervical lymph node metastasis were as follows: focal or diffuse hyperechogenicity, micro- or macrocalcification, cystic change; an abnormal vascular pattern (a chaotic or peripheral vascular pattern), and a round shape (long-transverse diameter ratio, <1.5). ${ }^{30-32}$ The final diagnoses of lymph nodes at each level were determined on the basis of the pathology reports regarding surgical specimens.

Study Design. Observational studies (retrospective or prospective) were included.

Outcomes. Results were reported in sufficient detail to evaluate the diagnostic performance of CT.

\section{Exclusion Criteria}

The exclusion criteria were the following: 1) case reports and series with a sample size of $<10$ patients and studies with a potential selection bias (eg, nonconsecutive series); 2) review articles, editorials, letters, comments, and conference proceedings; 3 ) studies on topics other than using CT to diagnose cervical lymph node metastasis in patients with papillary thyroid cancer; 4) studies with insufficient data to construct a $2 \times$ 2 table; and 5) studies with overlapping patients and data. Two reviewers (C.H.S. and J.H.B.) independently selected the studies from the literature.

\section{Data Extraction}

We extracted the following data from the selected literature studies onto standardized data forms: 1) study characteristics: authors, year of publication, hospital or medical school, duration of patient recruitment, study design, and sample size; 2) demographic and clinical characteristics of the patients: mean age, analysis methods, and criteria of CT and US for diagnosing cervical lymph node metastasis; and 3) the diagnostic performance of CT and US. One reviewer (C.H.S.) extracted data from the studies, and the second reviewer (J.H.B.) double-checked the accuracy of the extracted data.

\section{Quality Assessment}

The methodologic quality of the included studies was independently assessed by 2 reviewers (C.H.S. and J.H.B.) by using tailored questionnaires and criteria provided by Quality Assessment of Diagnostic Accuracy Studies-2 (QUADAS-2). ${ }^{33}$

\section{Data Synthesis and Analyses}

The diagnostic performances of CT and US were assessed as the main indices for this meta-analysis. First, a meta-analysis for all of the included studies was performed by using level-by-level and patient-based analyses. Second, we performed meta-analyses on the basis of the central and lateral neck levels. 


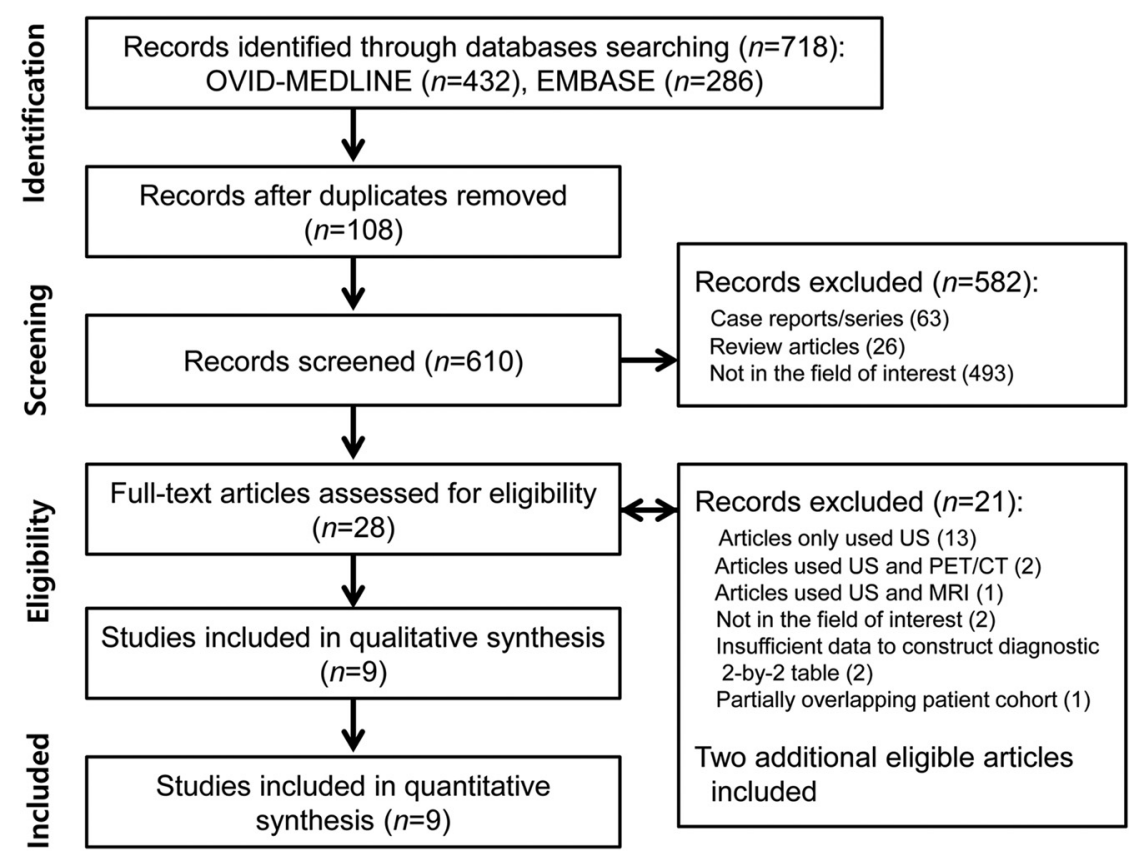

FIG 1. Flow diagram of the study selection process.

Heterogeneity among the studies was determined by using the Higgins $\mathrm{I}^{2}$ statistics $(0 \%-40 \%$, might not be significant; $30 \%-60 \%$, may represent moderate heterogeneity; 50\%-90\%, may represent substantial heterogeneity; and $75 \%-100 \%$, may represent considerable heterogeneity). ${ }^{34}$ When heterogeneity was noted, heterogeneity caused by a "threshold effect" was analyzed by visual assessment of the coupled forest plots of the sensitivity and the specificity. A meta-analysis of diagnostic test accuracy studies jointly analyzes a pair of outcomes (ie, sensitivity and specificity). Sensitivity and specificity are generally inversely correlated and affected by the threshold effect. ${ }^{25-27}$ Additionally, the Spearman correlation coefficient between the sensitivity and the false-positive rate was also obtained. A Spearman correlation coefficient of $>0.6$ indicates a considerable threshold effect. ${ }^{35}$

The summary sensitivity and specificity values were calculated by the using hierarchic summary receiver operating characteristic (HSROC) and bivariate random-effects modeling. ${ }^{25-27} \mathrm{We}$ obtained the diagnostic odds ratio, which is a single parameter of diagnostic accuracy. ${ }^{27}$ The HSROC curve with a 95\% confidence region and prediction region was also plotted to graphically present the results. Summarizing the results of original studies with the HSROC curve rather than by using summary points, including summary sensitivity or summary specificity, is recommended. ${ }^{27}$ We obtained the area under the curve from the HSROC curve. If a test is perfectly accurate, the value of the area under the curve is 1.0 and decreases toward 0.5 as the diagnostic accuracy of the test decreases.

Publication bias was visually assessed by using the Deeks funnel plot, and the statistical significance was tested by using the Deeks asymmetry test. We used the MIDAS and METANDI modules in STATA 10.0 (StataCorp, College Station, Texas) to perform the statistical analyses.

\section{RESULTS \\ Literature Search}

Our study selection process is described in Fig 1. The literature search of the Ovid-MEDLINE and EMBASE data bases initially generated 718 articles, and 610 articles were screened for eligibility after removing 108 duplicates. Of the remaining articles, 582 were excluded after reviewing the titles and abstracts, including 493 articles that were not in the field of interest (ie, they did not discuss the diagnostic performance of CT for evaluating cervical lymph node metastasis in patients with papillary thyroid cancer), 63 case reports or series containing $<10$ relevant patients, and 26 review articles. The full texts of the remaining 28 articles were then retrieved. Searches of the bibliographies of articles identified 2 additional, eligible studies. ${ }^{14,22}$ Of these 30 articles, 21 were further excluded after reviewing the full text (ie, 13 studies that only used US, 2 studies that used US and PET/CT, 1 study that used US and MR imaging, 2 studies that were not in the field of interest, 2 studies that reported insufficient data to construct a diagnostic 2-by-2 table, and 1 study with a partially overlapping patient cohort). Finally, 9 eligible studies, including a total sample size of 1691 patients, were included in this meta-analysis. ${ }^{14-22}$

\section{Characteristics of the Included Studies}

The detailed characteristics of the 9 included studies are summarized in the On-line Table. Three of the included studies were prospective, ${ }^{14,20,21}$ and the remaining 6 were retrospective. ${ }^{15-19,22}$ The CT criteria for cervical lymph node metastasis were similar in studies using morphologic criteria, though 4 studies added size criteria. ${ }^{14,15,20,21}$ The US criteria for cervical lymph node metastasis were variable. The final diagnoses of cervical lymph nodes were determined on the basis of the pathology reports of surgical specimens in all of the included studies. ${ }^{14-22}$ The quality of the included studies, as assessed by using QUADAS-2, was moderate overall, and all the studies satisfied $\geq 6$ of the 7 items (Fig 2). ${ }^{33}$

\section{Diagnostic Performance of CT and US for All Cervical Lymph Nodes by Level-by-Level Analysis}

Data were collected from 7 CT studies with 926 patients concerning the diagnostic performance of CT. ${ }^{14-17,19-21}$ The sensitivities and specificities of the individual studies were $35 \%-77 \%$ and 70\%-96\%, respectively. The Higgins $I^{2}$ statistics demonstrated a substantial heterogeneity regarding both sensitivity $\left(\mathrm{I}^{2}=82.6 \%\right)$ and specificity $\left(\mathrm{I}^{2}=89.7 \%\right.$ ). The coupled forest plots of the sensitivity and specificity revealed a threshold effect (Fig 3), and the Spearman correlation coefficient between the sensitivity and the false-positive rate was 0.807 (95\% CI, 0.136-0.970), thus also indicating the presence of the threshold effect.

The pooled sensitivities and specificities of CT and US are 


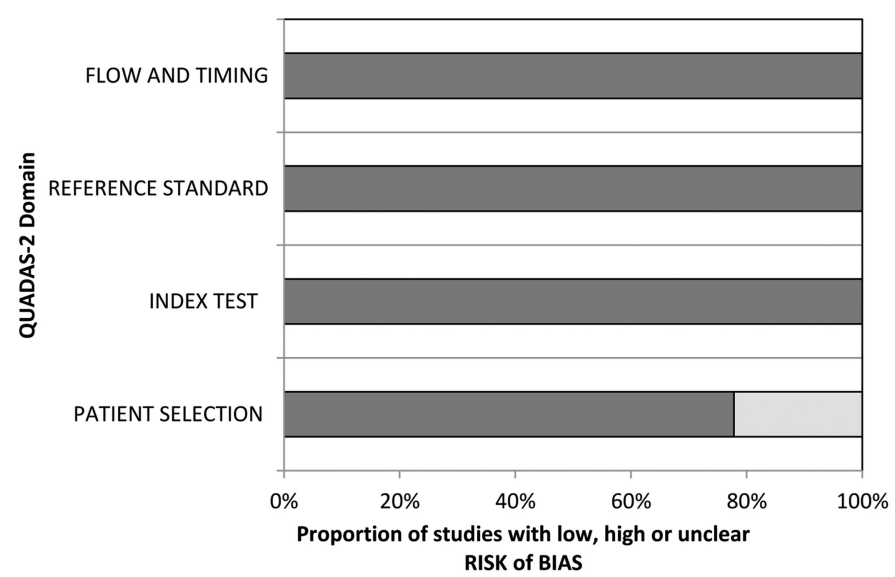

FIG 2. Quality Assessment of the Diagnostic Accuracy Studies-2 criteria for the included studies.

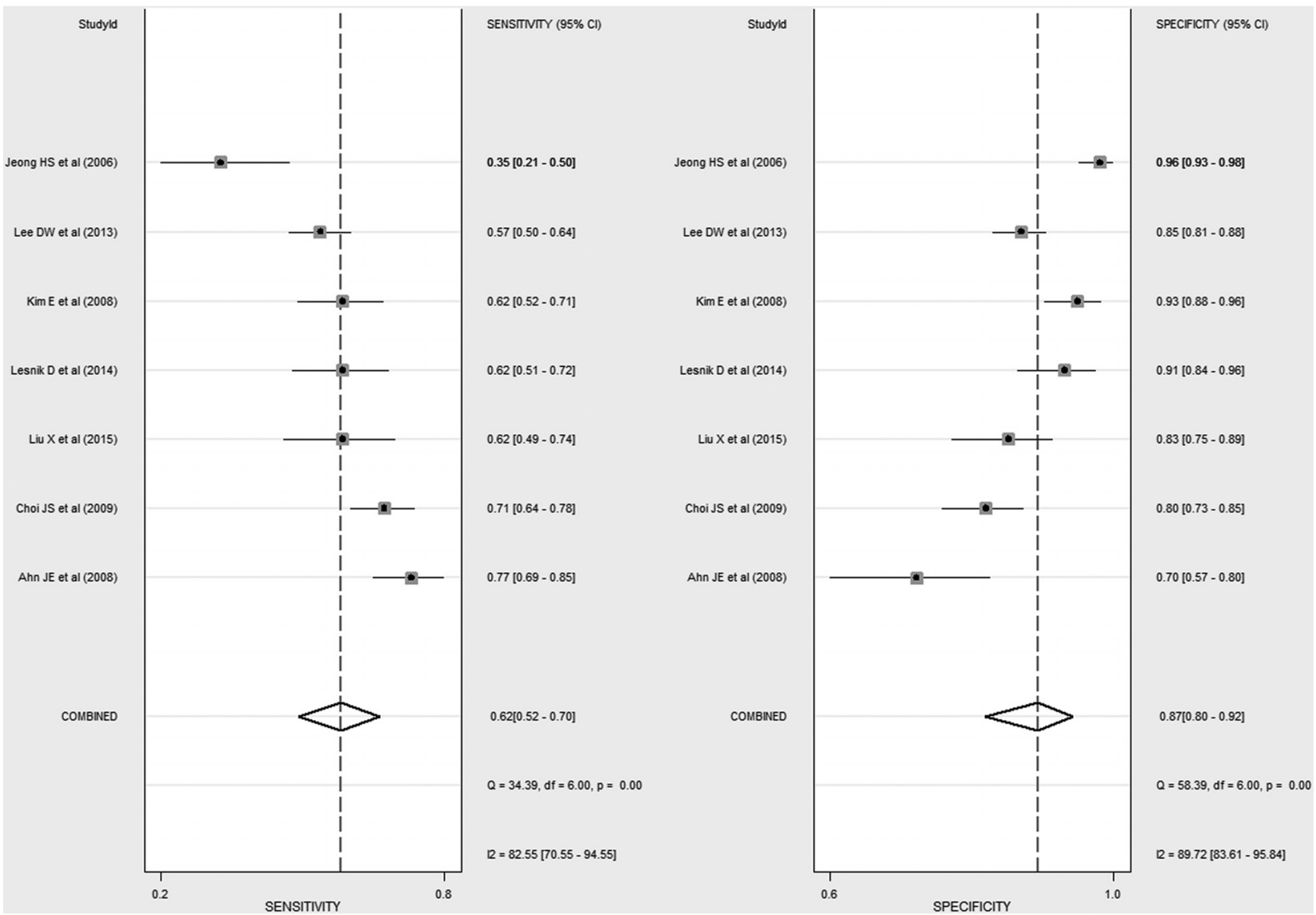

FIG 3. Coupled forest plots of the sensitivity and specificity of CT for diagnosing cervical lymph node metastasis in patients with papillary thyroid cancer. Horizontal lines indicate $95 \% \mathrm{Cls}$ of the individual studies.

summarized in the Table. CT demonstrated a summary sensitivity of $62 \%(95 \%$ CI, $52 \%-70 \%)$ and a specificity of $87 \%(95 \% \mathrm{CI}$, $80 \%-92 \%)$. The diagnostic odds ratio was 11 (95\% CI, 8-15). The HSROC curve was symmetric, and there was only a small difference between the $95 \%$ confidence region and the $95 \%$ prediction region, thus indicating little heterogeneity between the studies (Fig 4). The area under the HSROC curve was 0.80 (95\% CI, $0.77-0.84)$. No significant publication bias existed among the studies $(P=.41)$ (Fig 5$)$.

Data were collected from 6 US studies with 874 patients. ${ }^{14-17,19,20}$
The sensitivities and specificities of the individual studies were $40 \%-66 \%$ and $79 \%-96 \%$, respectively. The Spearman correlation coefficient between the sensitivity and false-positive rate was 0.960 (95\% CI, 0.675-0.996), thus indicating the presence of the threshold effect. US demonstrated a summary sensitivity of $51 \%$ (95\% CI, $42 \%-60 \%)$ and a specificity of $91 \%$ (95\% CI, $85 \%-$ $95 \%)$. The diagnostic odds ratio was 11 (95\% CI, 7-16). The area under the HSROC curve was 0.74 . The summary estimates of sensitivity $(P=.127)$ and specificity $(P=.351)$ did not differ between CT and US. 
Results of meta-analytic summary estimates of CT and US for diagnosing cervical lymph node metastasis in patients with papillary thyroid cancer by level-by-level analysis

\begin{tabular}{lcccc}
\hline & \multicolumn{3}{c}{ Meta-Analysis Summary Estimate } \\
\cline { 2 - 5 } & $\begin{array}{c}\text { Sensitivity } \\
(95 \% \mathrm{Cl})\end{array}$ & $\begin{array}{c}\boldsymbol{P} \\
\text { Value }\end{array}$ & $\begin{array}{c}\text { Specificity } \\
(95 \% \mathrm{CI})\end{array}$ & $\begin{array}{c}\boldsymbol{P} \\
\text { Value }\end{array}$ \\
\hline All cervical lymph nodes & & & & \\
US & $51 \%(42-60)$ & & $91 \%(85-95)$ & \\
CT & $62 \%(52-70)$ & $.127^{\mathrm{a}}$ & $87 \%(80-92)$ & $.351^{\mathrm{a}}$ \\
Combined CT/US & $69 \%(61-77)$ & $.011^{\mathrm{b}}$ & $81 \%(74-87)$ & $.074^{\mathrm{b}}$ \\
Lateral cervical lymph nodes & & & & \\
US & $71 \%(57-82)$ & & $85 \%(64-95)$ & \\
CT & $70 \%(59-80)$ & $.858^{\mathrm{a}}$ & $89 \%(81-94)$ & $.792^{\mathrm{a}}$ \\
Combined CT/US & $90 \%(80-95)$ & $.029^{\mathrm{b}}$ & $70 \%(43-88)$ & $.329^{\mathrm{b}}$ \\
Central cervical lymph nodes & & & & \\
US & $38 \%(27-52)$ & & $91 \%(81-96)$ & $.368^{\mathrm{a}}$ \\
CT & $57 \%(43-69)$ & $.088^{\mathrm{a}}$ & $85 \%(72-92)$ & $.281^{\mathrm{b}}$ \\
Combined CT/US & $57 \%(45-68)$ & $.079^{\mathrm{b}}$ & $83 \%(75-89)$ & \\
\hline
\end{tabular}

${ }^{a}$ Comparison for CT vs US

${ }^{\mathrm{b}}$ Comparison for combined CT/US vs US.

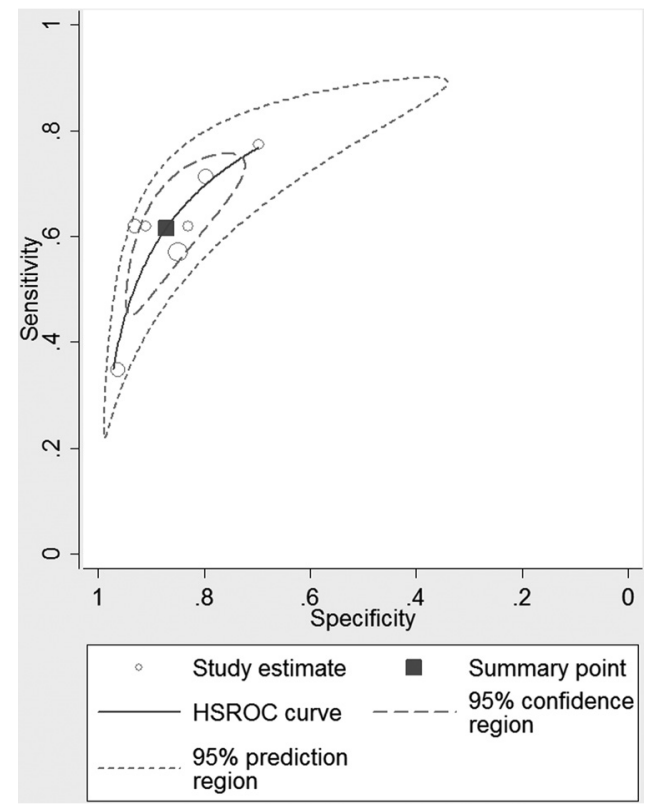

FIG 4. Hierarchic summary receiver operating characteristic curve of the performance of CT for diagnosing cervical lymph node metastasis in patients with papillary thyroid cancer.

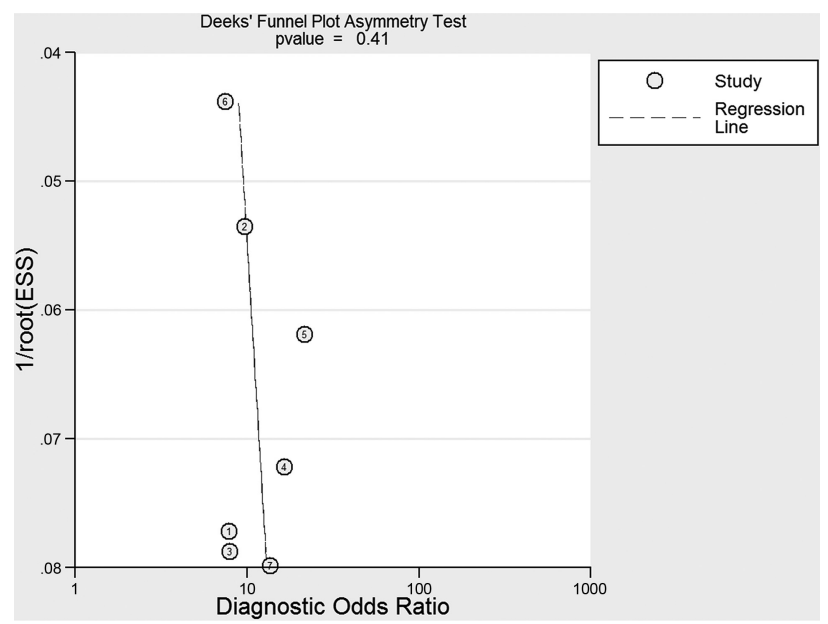

FIG 5. The Deeks funnel plot to evaluate publication bias.

\section{Comparison of CT and US according to Lateral and Central Cervical Lymph Nodes by Level-by- Level Analysis}

Concerning the lateral cervical lymph nodes, CT demonstrated a summary sensitivity of $70 \%$ (95\% CI, 59\%-80\%) and a specificity of $89 \%$ (95\% CI, 81\%$94 \%$ ) and US demonstrated a summary sensitivity of $71 \%$ (95\% CI, 57\%-82\%) and a specificity of $85 \%$ (95\% CI, 64\%95\%) (Table). The summary estimates of sensitivity $(P=.858)$ and specificity $(P=.792)$ did not differ between CT and US. Regarding central cervical lymph nodes, CT demonstrated a summary sensitivity of 57\% (95\% CI, 43\%$69 \%$ ) and a specificity of $85 \%$ (95\% CI, $72 \%-92 \%$ ), and US demonstrated a summary sensitivity of $38 \%$ (95\% CI, 27\%-52\%) and a specificity of $91 \%$ (95\% CI, $81 \%-$ $96 \%)$. Although the summary sensitivity of CT was higher than that of US, there was no significant difference $(P=.088)$. The summary specificity $(P=.368)$ did not differ between CT and US.

\section{Added Value of Combined CT/US by Level-by-Level Analysis}

Four studies reported combined CT/US for diagnosing cervical lymph node metastasis. ${ }^{16,17,19,20}$ The sensitivity ranged from $61 \%$ to $80 \%$, and the lower margin of the $95 \%$ CI reached $54 \%$. The specificity ranged from $69 \%$ to $88 \%$, and the lower margin of the 95\% CI reached $62 \%$. Combined CT/US demonstrated a summary sensitivity of $69 \%(95 \% \mathrm{CI}, 61 \%-77 \%)$ and a specificity of $81 \%$ (95\% CI, 74\%-87\%). The summary sensitivity of combined $\mathrm{CT} / \mathrm{US}$ was significantly higher than that of US $(P=.011)$, though the summary specificity did not differ $(P=.074)$.

\section{Performance of CT and US for Diagnosing Cervical Lymph Node Metastasis by Patient-Based Analysis}

Pooling was not performed due to the relatively small number of studies $(n=4)$ used for these analyses. ${ }^{16,18,19,22}$ The sensitivity of CT was variable, ranging from $31 \%$ to $59 \%$; and the lower margin of the $95 \%$ CI reached $22 \%$. The specificity of CT ranged from $84 \%$ to $94 \%$, and the lower margin of the $95 \%$ CI reached $77 \%$. The sensitivity of US was variable, ranging from $24 \%$ to $47 \%$, and the lower margin of the $95 \%$ CI reached $17 \%$. The specificity of US ranged from $80 \%$ to $92 \%$, and the lower margin of the $95 \%$ CI reached $74 \%$.

\section{DISCUSSION}

Our current systematic review with a meta-analysis demonstrated that CT showed a summary sensitivity of $62 \%$ and a specificity of $87 \%$ for diagnosing cervical lymph node metastasis in patients with papillary thyroid cancer by a level-by-level analysis. There was a positive correlation between the sensitivity and the falsepositive rate (correlation coefficient of 0.807 ) because of the threshold effect. In terms of the comparison of CT and US, the summary estimates of the sensitivity and specificity did not differ 
between CT and US for all cervical lymph nodes and lateral/central lymph nodes. However, the summary sensitivity of combined CT/US (69\%) was significantly higher than that of US (51\%), though the summary specificity did not differ. These results suggest that the diagnostic performances of CT and US are similar but that CT and US combined are superior to US only for the detection of cervical lymph node metastasis in patients with papillary thyroid cancer by a level-by-level analysis.

During the past decade, many studies have described the diagnostic performance of CT for cervical lymph node metastasis in patients with papillary thyroid cancer. ${ }^{14-22}$ CT is a standardized, objective imaging technique that is less operator-dependent compared with US. In addition, CT provides detailed axial anatomic information systematically from the base of the skull to the mediastinum, which is familiar to most thyroid surgeons. Moreover, CT can evaluate lymph nodes in the retropharyngeal, retrosternal, and mediastinal areas. ${ }^{20}$ As the new American Thyroid Association guidelines suggest, CT can also be useful for evaluating the tumor extent involving the larynx, trachea, or esophagus as well as showing extranodal extension involving surrounding critical structures. ${ }^{7}$ Our meta-analysis revealed that the summary sensitivity of combined CT/US (69\%) was significantly higher than that of US (51\%) $(P=.011)$. This improved sensitivity of combined CT/US allows better surgical planning and a better chance for removing all suspected cervical lymph node metastasis during surgery. Therefore, we believe that combined CT/US may have a supportive role, especially for preoperative surgical planning in patients with suspected lymph node metastasis or a high-risk of lymph node metastasis. ${ }^{16,23}$

The use of iodine-based contrast materials was strongly restricted before the operation due to the concern for disturbed radioactive iodine uptake for months and the delay of radioiodine treatment. $^{36}$ Therefore, contrast-enhanced CT has not been recommended for the preoperative diagnosis of cervical lymph node metastasis. However, several recent studies have reported the supposition that the delay of radioiodine therapy was not necessary in patients who underwent contrast-enhanced CT because the iodine is generally cleared within $4-8$ weeks in most patients, and the body iodine content is not an essential determinant of thyroid ablation. ${ }^{37-41}$ Therefore, the benefit gained from improved anatomic imaging generally outweighs any potential risk regarding a several-week delay in radioactive iodine imaging or therapy.

In our meta-analysis, our summary estimates demonstrate consistent results despite heterogeneity. The Higgins $\mathrm{I}^{2}$ statistic demonstrated a substantial heterogeneity in both the sensitivity $\left(\mathrm{I}^{2}=82.6 \%\right)$ and specificity $\left(\mathrm{I}^{2}=89.7 \%\right)$ of CT. However, there was a positive correlation between and sensitivity and the falsepositive rate (correlation coefficient of 0.807 ), which would be expected in a meta-analysis of diagnostic test accuracy studies due to the threshold effect. This correlation indicates that our heterogeneity was mainly caused by the threshold effect. CT criteria for cervical lymph node metastasis in our included studies were similar, though several studies used not only morphologic criteria but also size criteria, which may cause the threshold effect. ${ }^{26,27}$ Morphologic criteria include central necrosis or cystic change, strong enhancement without hilar vessel enhancement, calcification, and round shape with loss of the fatty hilum (On-line Table). The possibility of a node with only mild enhancement would be very low for lymph node metastasis. In addition, the US criteria for cervical lymph node metastasis were also variable between studies. The US criteria included cystic change, the absence of a hilum, microcalcification, heterogeneity, and size.

We used validated systematic review methods and reported our data according to standard reporting guidelines, including the Preferred Reporting Items for Systematic Reviews and MetaAnalyses (PRISMA), ${ }^{42}$ the guidelines of the Handbook for Systematic Reviews of Diagnostic Test Accuracy by the Cochrane Collaboration, ${ }^{43}$ and the guidelines of the Agency for Healthcare Research and Quality. ${ }^{44}$ We determined the diagnostic performance of CT by using more recently developed robust methodology (ie, the HSROC model or the bivariate random-effects model). ${ }^{25-27}$ Therefore, this study, which gathered currently available evidence, was needed and will help to advance daily clinical practice.

Our study had several limitations. First, it included relatively few studies (ie, 9). In addition, the sample size of the number of included studies in the meta-analysis according to the central/ lateral lymph nodes was small. Nonetheless, a small number of statistically significant differences were elucidated. Second, as addressed earlier, the CT or US criteria for cervical lymph node metastasis were similar but somewhat variable between studies because no consistent criteria have been established regarding cervical lymph node metastasis. The threshold effect is probably caused by these variable criteria. Third, 7 of 9 studies included reflect single-country data; however, these are the only available studies. ${ }^{14-19,22}$ Fourth, the specificity of combined $\mathrm{CT} / \mathrm{US}$ is lower than that of US alone; however, it is not statistically significant.

\section{CONCLUSIONS}

The diagnostic performances of CT and US are similar, though CT and US combined are superior to US only for the detection of cervical lymph node metastasis in patients with papillary thyroid cancer by a level-by-level analysis. CT may be used as a complementary method in addition to US for diagnosing cervical lymph node metastasis in patients with papillary thyroid cancer.

\section{REFERENCES}

1. Mulla M, Schulte KM. Central cervical lymph node metastases in papillary thyroid cancer: a systematic review of imaging-guided and prophylactic removal of the central compartment. Clin Endocrinol (Oxf) 2012;76:131-36 CrossRef Medline

2. Rotstein L. The role of lymphadenectomy in the management of papillary carcinoma of the thyroid. J Surg Oncol 2009;99:186-88 CrossRef Medline

3. Sivanandan R, Soo KC. Pattern of cervical lymph node metastases from papillary carcinoma of the thyroid. Br J Surg 2001;88:1241-44 CrossRef Medline

4. Randolph GW, Duh QY, Heller KS, et al; American Thyroid Association Surgical Affairs Committee's Taskforce on Thyroid Cancer Nodal Surgery. The prognostic significance of nodal metastases from papillary thyroid carcinoma can be stratified based on the size and number of metastatic lymph nodes, as well as the presence of extranodal extension. Thyroid 2012;22:1144-52 CrossRef Medline

5. Zaydfudim V, Feurer ID, Griffin MR, et al. The impact of lymph node involvement on survival in patients with papillary and follicular 
thyroid carcinoma. Surgery 2008;144:1070-77; discussion 77-78; discussion 1077-78 CrossRef Medline

6. Mazzaferri EL, Doherty GM, Steward DL. The pros and cons of prophylactic central compartment lymph node dissection for papillary thyroid carcinoma. Thyroid 2009;19:683-89 CrossRef Medline

7. Haugen BR, Alexander EK, Bible KC, et al. 2015 American Thyroid Association Management Guidelines for Adult Patients with Thyroid Nodules and Differentiated Thyroid Cancer: the American Thyroid Association Guidelines Task Force on Thyroid Nodules and Differentiated Thyroid Cancer. Thyroid 2016;26:1-133 CrossRef Medline

8. Wu LM, Gu HY, Qu XH, et al. The accuracy of ultrasonography in the preoperative diagnosis of cervical lymph node metastasis in patients with papillary thyroid carcinoma: a meta-analysis. Eur J Radiol 2012;81:1798-805 CrossRef Medline

9. Ito $\mathrm{Y}$, Jikuzono $\mathrm{T}$, Higashiyama $\mathrm{T}$, et al. Clinical significance of lymph node metastasis of thyroid papillary carcinoma located in one lobe. World J Surg 2006;30:1821-28 CrossRef Medline

10. Sipos JA. Advances in ultrasound for the diagnosis and management of thyroid cancer. Thyroid 2009;19:1363-72 CrossRef Medline

11. Hwang HS, Orloff LA. Efficacy of preoperative neck ultrasound in the detection of cervical lymph node metastasis from thyroid cancer. Laryngoscope 2011;121:487-91 CrossRef Medline

12. Ha EJ, Baek JH, Lee JH. Ultrasonography-based thyroidal and perithyroidal anatomy and its clinical significance. Korean J Radiol 2015;16:749-66 CrossRef Medline

13. Cooper DS, Doherty GM, Haugen BR, et al; American Thyroid Association (ATA) Guidelines Taskforce on Thyroid Nodules and Differentiated Thyroid Cancer. Revised American Thyroid Association management guidelines for patients with thyroid nodules and differentiated thyroid cancer. Thyroid 2009;19:1167-214 CrossRef Medline

14. Jeong HS, Baek CH, Son YI, et al. Integrated 18F-FDG PET/CT for the initial evaluation of cervical node level of patients with papillary thyroid carcinoma: comparison with ultrasound and contrast-enhanced CT. Clin Endocrinol (Oxf) 2006;65:402-07 CrossRef Medline

15. Ahn JE, Lee JH, Yi JS, et al. Diagnostic accuracy of CT and ultrasonography for evaluating metastatic cervical lymph nodes in patients with thyroid cancer. World J Surg 2008;32:1552-58 CrossRef Medline

16. Kim E, Park JS, Son KR, et al. Preoperative diagnosis of cervical metastatic lymph nodes in papillary thyroid carcinoma: comparison of ultrasound, computed tomography, and combined ultrasound with computed tomography. Thyroid 2008;18:411-18 CrossRef Medline

17. Choi JS, Kim J, Kwak JY, et al. Preoperative staging of papillary thyroid carcinoma: comparison of ultrasound imaging and CT. AJR Am J Roentgenol 2009;193:871-78 CrossRef Medline

18. Choi YJ, Yun JS, Kook SH, et al. Clinical and imaging assessment of cervical lymph node metastasis in papillary thyroid carcinomas. World J Surg 2010;34:1494-99 CrossRef Medline

19. Lee DW, Ji YB, Sung ES, et al. Roles of ultrasonography and computed tomography in the surgical management of cervical lymph node metastases in papillary thyroid carcinoma. Eur J Surg Oncol 2013;39:191-96 CrossRef Medline

20. Lesnik D, Cunnane ME, Zurakowski D, et al. Papillary thyroid carcinoma nodal surgery directed by a preoperative radiographic map utilizing CT scan and ultrasound in all primary and reoperative patients. Head Neck 2014;36:191-202 CrossRef Medline

21. Liu X, Ouyang D, Li H, et al. Papillary thyroid cancer: dual-energy spectral CT quantitative parameters for preoperative diagnosis of metastasis to the cervical lymph nodes. Radiology 2015;275:167-76 CrossRef Medline

22. Na DK, Choi YJ, Choi SH, et al. Evaluation of cervical lymph node metastasis in thyroid cancer patients using real-time CT-navigated ultrasonography: preliminary study. Ultrasonography 2015;34:39-44 CrossRef Medline

23. Yeh MW, Bauer AJ, Bernet VA, et al; American Thyroid Association
Surgical Affairs Committee Writing Task Force. American Thyroid Association statement on preoperative imaging for thyroid cancer surgery. Thyroid 2015;25:3-14 CrossRef Medline

24. Tunis AS, McInnes MD, Hanna R, et al. Association of study quality with completeness of reporting: have completeness of reporting and quality of systematic reviews and meta-analyses in major radiology journals changed since publication of the PRISMA statement? Radiology 2013;269:413-26 CrossRef Medline

25. Suh $\mathrm{CH}$, Park SH. Successful publication of systematic review and meta-analysis of studies evaluating diagnostic test accuracy. Korean J Radiol 2016;17:5-6 CrossRef Medline

26. Kim KW, Lee J, Choi SH, et al. Systematic review and meta-analysis of studies evaluating diagnostic test accuracy: a practical review for clinical researchers, part I: general guidance and tips. Korean $\mathrm{J} \mathrm{Ra-}$ diol 2015;16:1175-87 CrossRef Medline

27. Lee J, Kim KW, Choi SH, et al. Systematic review and meta-analysis of studies evaluating diagnostic test accuracy: a practical review for clinical researchers, part II, statistical methods of meta-analysis. Korean J Radiol 2015;16:1188-96 CrossRef Medline

28. Edge S, Byrd DR, Compton CC, et al, eds. AJCC Cancer Staging Manual. 7th ed. New York: Springer; 2010:87-96

29. Som PM, Brandwein M, Lidov M, et al. The varied presentations of papillary thyroid carcinoma cervical nodal disease: CT and MR findings. AJNR Am J Neuroradiol 1994;15:1123-28 Medline

30. Na DG, Lim HK, Byun HS, et al. Differential diagnosis of cervical lymphadenopathy: usefulness of color Doppler sonography. AJR Am J Roentgenol 1997;168:1311-16 CrossRef Medline

31. Ying M, Ahuja A, Metreweli C. Diagnostic accuracy of sonographic criteria for evaluation of cervical lymphadenopathy. J Ultrasound Med 1998;17:437-45 Medline

32. Rosário PW, de Faria S, Bicalho L, et al. Ultrasonographic differentiation between metastatic and benign lymph nodes in patients with papillary thyroid carcinoma. J Ultrasound Med 2005;24: 1385-89 Medline

33. Whiting P, Rutjes AW, Reitsma JB, et al. The development of QUADAS: a tool for the quality assessment of studies of diagnostic accuracy included in systematic reviews. BMC Med Res Methodol 2003;3:25 CrossRef Medline

34. Higgins J, Green S. Cochrane Handbook for Systematic Reviews of Interventions. Version 5.1.0. Updated March 2011. http://handbook. cochrane.org/. Accessed August 15, 2015

35. Deeks JJ, Macaskill P, Irwig L. The performance of tests of publication bias and other sample size effects in systematic reviews of diagnostic test accuracy was assessed. J Clin Epidemiol 2005;58:882-93 CrossRef Medline

36. Spate VL, Morris JS, Nichols TA, et al. Longitudinal study of iodine in toenails following IV administration of an iodine-containing contrast agent. Journal of Radioanalytical and Nuclear Chemistry 1998;236:71-77 CrossRef

37. Padovani RP, Kasamatsu TS, Nakabashi CC, et al. One month is sufficient for urinary iodine to return to its baseline value after the use of water-soluble iodinated contrast agents in post-thyroidectomy patients requiring radioiodine therapy. Thyroid 2012;22:926-30 CrossRef Medline

38. Sohn SY, Choi JH, Kim NK, et al. The impact of iodinated contrast agent administered during preoperative computed tomography scan on body iodine pool in patients with differentiated thyroid cancer preparing for radioactive iodine treatment. Thyroid 2014;24: 872-77 CrossRef Medline

39. Ho JD, Tsang JF, Scoggan KA, et al. Urinary iodine clearance following iodinated contrast administration: a comparison of euthyroid and postthyroidectomy subjects. J Thyroid Res 2014;2014:580569 CrossRef Medline

40. Mishra A, Pradhan PK, Gambhir S, et al. Preoperative contrast-enhanced computerized tomography should not delay radioiodine ablation in differentiated thyroid carcinoma patients. J Surg Res 2015;193:731-37 CrossRef Medline

41. Tala Jury HP, Castagna MG, Fioravanti C, et al. Lack of association 
between urinary iodine excretion and successful thyroid ablation in thyroid cancer patients. J Clin Endocrinol Metab 2010;95:230-37 CrossRef Medline

42. Liberati A, Altman DG, Tetzlaff J, et al. The PRISMA statement for reporting systematic reviews and meta-analyses of studies that evaluate health care interventions: explanation and elaboration. PLoS Med 2009;6:e1000100 CrossRef Medline
43. Deeks JJ, Bossuyt PM, Gatsonis C, eds. Cochrane Handbook for Systematic Reviews of Diagnostic Test Accuracy. Version 1.0.0. The Cochrane Collaboration. 2013. http://srdta.cochrane.org/handbookdta-reviews. Accessed March 31, 2016

44. Trikalinos TA, Balion CM, Coleman CI, et al. Chapter 8: meta-analysis of test performance when there is a "gold standard." J Gen Intern Med 2012;27(suppl 1):S56-66 CrossRef Medline 